\title{
Em defesa da matemática
}

\author{
In defense of mathematics
}

Wesley de Jesus Barbosa ${ }^{1}$

Resumo: O presente artigo pretende fazer uma defesa da matemática, em especial, da matemática pura. Partindo de problemas colocados por Kant no que concerne às condições de um pensamento puro a priori, seguindo por indagações promovidas por Leibniz no sentido da construção de uma linguagem artificial capaz de acessar de forma mais segura o mundo, e atormentados pela desconexão estrutural entre a linguagem humana natural e o mundo, elencada pelo debate da Filosofia da Linguagem promovida pela Tradição Analítica, se quis realizar uma investigação no sentido de procurar um conhecimento que fosse essencialmente a priori. Apesar do projeto logicista de Frege, ainda não foi possível uma linguagem totalmente artificial que expressasse o mundo sem suas ambiguidades. Entretanto, pistas indicam que a matemática pura, que tem como substrato a lógica, é uma linguagem formal poderosamente capaz de construir axiomas.

Palavras-chave: Axiomas. Filosofia. Linguagem. Matemática.

Abstract: This article intends to defend mathematics, especially pure mathematics. Starting from problems posed by Kant regarding the conditions of pure a priori thinking, followed by inquiries promoted by Leibniz towards the construction of an artificial language capable of accessing the world more safely, and plagued by the structural disconnection between language natural human and the world, listed by the debate on the Philosophy of Language promoted by Analytical Tradition, if we wanted to carry out an investigation in the sense of seeking knowledge that was essentially a priori. Despite Frege's logicist project, it has not yet been possible for a completely artificial language to express the world without its ambiguities. However, clues indicate that pure mathematics, which has logic as its substrate, is a formal language powerfully capable of constructing axioms.

Keywords: Axioms. Pilosophy. Language. Mathematics.

\section{Introdução}

É, pois, plausível pensar que exista, unido a um sinal (nome, combinação de palavras, letras), além daquilo por ele designado, que pode ser chamado de sua referência (Bedeutung), ainda o que eu gostaria de chamar de o sentido (Sinn) do sinal, onde está

\footnotetext{
${ }^{1}$ Mestre em Filosofia pela Universidade Federal do Espírito Santo (UFES). Artigo recebido em 24 de maio de 2020 aceito em 04 de agosto de 2020. E-mail: wesleydejesusbarbosa1980@ gmail.com.
} 
contido o modo de apresentação do objeto. (FREGE, 1892, p. 131)

Frege salienta que uma sentença pode ter sentido e referência, assim como pode ter sentido e ser desprovida de referência. A discussão que ele promove versa sobre o julgamento das sentenças como tendo valores de verdade: verdadeiro ou falso. Para que sejam falsas, as sentenças não teriam sentido, nem referência, enquanto para se julgar verdadeiras necessitam, obrigatoriamente, de sentido e referência, ou seja, algo no mundo tem que indicar empiricamente o sinal o qual se remete o sentido. Se nada no mundo indica o sentido, não há referência. A preocupação de Frege sobre se a linguagem consegue se referir as coisas não é obvia, há muitos mal-entendidos, ruídos entre as linguagens naturais e ao que elas se referem. É por causa desta dificuldade que Frege tentou montar uma linguagem formal no qual pudesse reduzir os ruídos. A lógica que ainda vigorava no século XIX era a silogística, um projeto mais ambicioso tinha que ser iniciado. Não é difícil imaginar que a matemática possui muitos dos recursos dos quais a filosofia pode se utilizar para tatear o real com mais certeza e Frege irá a ela para construir seu sistema.

Leibniz, por sua vez, também ambicionava criar uma linguagem completamente artificial que pudesse reescrever em sentenças menores e mais simples, as inumeráveis sentenças prolixas que elaboramos o tempo todo para explicar as coisas. Pois, como Frege, considerava que não existe uma exatidão no que se refere às palavras e as coisas ${ }^{2}$. Desde a origem da linguagem, com seus usos e suas regras, no contexto biossocial específico, a língua sofreu mudanças, ainda que houvesse um substrato rígido de regras como norteador, algo saia do normativo e tomava formas distintas da original. "Dropar uma onda" não tem o menor sentido para filósofos, a não ser que ele seja surfista; em Vitória no estado do Espírito Santo se come mandioca ou aipim, mas em Fortaleza se come macaxeira, por causa da região houve uma variação da palavra, mas ainda operamos no universo conceitual da língua portuguesa. Leibniz esboça uma tentativa de investigação no sentido de promover uma arqueologia da linguagem investigando dentro de um sistema causal, em direção à sentença original; e se lá, chegássemos, de lá

\footnotetext{
${ }^{2}$ Não é minha intenção escrever sobre uma história da lógica, por isso é importante indicar que a ordem ou sequência expositiva dos autores ao longo do texto não obedece à cronologia histórica dos acontecimentos. Diferentemente, insere-se na dinâmica cognitiva da produção dos argumentos, haja vista, a defesa da matemática.

Perspectivas - Revista do Programa de Pós-Graduação em Filosofia da UFT - volume 5, n. 1 - 2020
} 
conseguiríamos argumentos coincidentes ao mundo. Leibniz considera que este não é o caminho, pois ainda garimpamos no terreno das linguagens naturais. Sair deste terreno é condição necessária para uma linguagem menos ambígua e a matemática tem as condições para tal empreitada.

Kant, ainda, se pergunta sobre a possibilidade dos juízos sintéticos a priori na Crítica da Razão Pura, faz uma crítica à razão pura reposicionando-a no mundo; para ele há conhecimentos a priori e é deles que devemos partir para entender a realidade empírica. As categorias a priori do entendimento são fundamentais para a explicação e compreensão dos fenômenos. Ora, se a razão pura consegue enumerar os juízos sintéticos a priori, não é inverossímil pensar que a matemática enquanto pensamento puro, fortemente alicerçada na lógica elencasse proposições que por si mesmas fossem verdadeiras. E, se, inicialmente, nada falem sobre o mundo, e defendo que não devam se preocupar mesmo com o mundo, em outro momento, isto que é substancialmente formal pode ser útil ao mundo, referindo-se a ele ou resolvendo problemas pontuais relativos a ele. Assim como da razão pura se vai ao mundo, da matemática pura encontra-se segredos desvelados em axiomática.

Por tudo isto, o objetivo principal deste artigo é promover uma defesa da matemática pura contra os ataques desferidos por aqueles que consideram seu exercício perda de tempo, são eles, os tecnicistas tomados pela execução objetiva e repetitiva de mecanismos, os instrumentalistas utilitaristas, os pragmáticos e sua desistência voluntária e pública, pelo cansaço da tarefa, de mergulhar ao fundo das coisas. Pois que seduzidos pelo imediatismo da vida contemporânea, já não se dão conta que as maravilhas da matemática aplicada são produto de uma dedicação sacerdotal ao desenvolvimento de postulados. Para isto, enumeramos outros objetivos, secundários, tais como:

i. Exposição inicial dos argumentos de Frege, Leibniz e Kant no sentido de demonstrar ao leitor as desconfianças com relação às linguagens naturais e o mundo;

ii. Apresentar os apontamentos que indicam a matemática como ferramenta objetiva capaz de acessar o mundo com maior certeza;

iii. Justificar o argumento da precisão matemática a partir dos cinco postulados de Euclides. 


\section{Se as palavras e o mundo são coincidentes}

A realidade do mundo e dos homens não são triviais. A linguagem é o principal mecanismo de acesso do homem ao mundo, é com ela que significamos o mundo, damos sentido a ele, elaboramos suas nuances e construímos narrativas capazes de inscrever o mundo como cultura humana possível de ser transmitida geração a geração.

Entretanto, não é de se espantar que alguns filósofos explicitaram uma certa desconfiança com relação a essa linguagem de acesso ao mundo. "Assim, acontece que há uma forma de pleonasmo nas percepções que temos das qualidades sensíveis, como também das massas sensíveis, pleonasmo que consiste em possuirmos mais do que uma noção do mesmo sujeito.” (LEIBNIZ, 1765, p. 288). Para eles não é tão óbvio que esta linguagem de signos acesse a realidade das coisas de uma forma efetivamente coerente, pois o problema que se coloca é que ao se predicar o sujeito, há no conteúdo semântico da própria predicação uma ambiguidade constitutiva, o que impede uma exatidão expositiva do fenômeno. "Creio que o arbitrário reside somente nas palavras, de forma alguma nas ideias.” (LEIBNIZ, 1765, p. 289).

Em Kant no seu memorável Crítica da Razão Pura somente o fenômeno é o que aparece enquanto realidade, sendo a coisa-em-si impossível de acessarmos. Ora, portanto a análise dos fenômenos dar-se-á na condição da exposição das categorias a priori, que não sendo diretamente influenciadas pelo mundo sensível estão para além do mundo. "O verdadeiro problema da razão pura está contido na pergunta: como são possíveis juízos sintéticos a priori?" (KANT, 1781, p. 62). Assim, a condição de elucidação destas categorias, juízos sintéticos, consolida um lugar da razão que é pura, ou seja, esta encapsulada na própria redoma de si, movimentando-se cognitivamente nas condições

particulares de sua regra. Kant ao afirmar essa razão pura como dorsal no entendimento do mundo, critica a tradição que negou-se a elaborar uma crítica desta razão pura. Porque pura, a razão esteve longe do mundo e distante do mundo negou-se a comentar sobre ele. O pensamento puro precisa ir ao mundo para não se perder no vazio de suas manobras intelectuais. Mas, ao mesmo tempo, o pensamento puro tem que conduzir-se solitário, sem os vícios do mundo, para consolidar uma verdade humana o qual se agarrar. Como garantir uma razão pura, ou como garantir uma razão pura que não seja tão particular como se fosse um delírio? Pois, 
$\mathrm{Na}$ solução do problema precedente está ao mesmo tempo incluída a possibilidade de o uso puro da razão fundar e levar a cabo todas as ciências que contém um conhecimento teórico a priori de objetos, isto é, responder às perguntas:

Como é possível a matemática pura?

Como é possível a ciência pura da natureza? (KANT, 1781, p. $63)$.

Se em Leibniz a questão é a de formular uma linguagem artificial, isto porque as linguagens naturais são ambíguas; em Kant, o problema permanece e a solução parece ter semelhanças, pois, de saída, o em-si das coisas é negado como completamente impossível e o que acessamos pelo entendimento é, apenas, o fenômeno. Todavia, o acontecimento fenomenal não nos é óbvio como se fosse apenas abrir os olhos e entender, ir ao fenômeno se dá pela razão e esta pode ser uma razão inscrita no mundo ou uma razão pura, ou seja, sem o mundo. A matemática constrói o conceito de quantidade sendo ele intuitivo, enquanto as qualidades são empiricamente constituídas. A dualidade do mundo não é evidente em Kant, o dentro do homem não determina o fora (idealismo) ou, ao contrário, o fora como sendo em si mesmo uma totalidade independente do homem (empirismo); há o mundo das coisas no mundo dos homens, o mundo dos homens nas coisas do mundo, o mundo das coisas na realidade do homem-mundo, há uma subjetividade enquanto mente racional que não determina o mundo (objetividade) porque o mundo existe, afinal. É uma subjetividade que sendo objetividade cria sistemas racionais que operam no real conceituando-o em qualidades ou quantidades.

Aqueles que pensavam poder distinguir a filosofia da matemática ao afirmarem que a primeira possui como objeto tão-somente a qualidade e a segunda unicamente a quantidade tomaram o efeito como sendo a causa. A forma do conhecimento matemático é a causa que o constrange a se limitar exclusivamente as quantidades. Com efeito, só o conceito de quantidade é passível de ser construído, isto é, apresentado a priori na intuição; as qualidades, no entanto, não podem ser apresentadas em nenhuma outra intuição que não a empírica. Em decorrência disto, um conhecimento racional das qualidades só é possível através dos conceitos. Deste modo, ninguém pode obter uma intuição correspondente ao conceito da realidade senão a partir da experiência, e jamais é possível que dela nos apoderemos a priori a partir de nós mesmos antes de possuirmos uma consciência empírica da mesma (KANT, 1781, p. 431).

Leibniz e Kant sugerem como estratégia para explicar o mundo distanciar-se dele por algum momento, Leibniz de forma mais radical, Kant promovendo um corte epistemológico no binarismo mundo/homem, fenômeno/mente, apontando para os juízos sintéticos a priori, habitantes de uma razão pura, para desta linguagem sem vícios 
desvelar o mundo. Ora, a razão prática, empírica, típica das ciências (Física) tem como substrato o pensamento puro com sua principal porta-voz: a matemática pura.

A presente proposta de trabalho dedicar-se-á a realizar uma defesa. Seduzidos pelo pragmatismo e o utilitarismo das ciências modernas, acabamos por nos tornarmos práticos demais e outorgamos como fato indubitável a realidade das coisas; e se já obtemos um método experimental e replicável, já não ansiamos mais nada porque já conhecemos mesmo, as coisas.

Descartes não parece retomar o conceito aristotélico de abstração. $\mathrm{O}$ objeto matemático é identificado a uma função: apresentar a extensão por meio de símbolos que sãos instituídos por meio de um critério pragmático, visto que não são pensados sob uma perspectiva ontológica. (OLIVEIRA, 2009, p. 91).

A matemática pura, isto é, o pensamento puro, perdeu seu charme, apesar de homens de imensa envergadura intelectual ainda resistirem bravios nas trincheiras epistemológicas de um saber que não seja somente uma techné, sem uma compreensão dos motivos por trás do funcionamento das máquinas, de Poincaré a Einstein e Heisenberg, passando por George Ellis e Max Tegmark, a matemática é enaltecida por sua robusta consistência teórica e metodológica. O pensamento puro, sem o mundo, não é uma profunda perda de tempo dos espíritos mais ociosos, não é um engano da razão que já até se esqueceu do mundo, não é um divertimento das mentes lógicas que se lançam no interior de seus puzzle; o pensamento puro, a matemática pura tem um comprometimento ético com a verdade e, por mais que, estejamos sedentos, porque estamos imersos neste contexto histórico específico, de explicações mais rápidas, talvez até superficiais, não devemos censurar essas cabeças como se fossem aloprados mentais.

A posição cartesiana nas Règles é duplamente singular: inicialmente, sobre o plano conceitual, por ser refratária ao conceito de abstração aristotélico, no que tange à instituição do objeto matemático. Em seguida, sobre o plano ontológico, pela compreensão da intuição como uma realização do olhar que considera a coisa como uma quantidade passível de ser traduzida por símbolos matemáticos, sem inscrever, contudo, esses símbolos no terreno de uma ontologia. A consequência para as matemáticas dessa postura cartesiana é a instituição de uma álgebra que não reconhece mais limites ontológicos entre a aritmética e a geometria, pois considerando que o objeto matemático nas Règles é abstrato (no sentido cartesiano), esses objetos podem se aplicar às diferentes variações das grandezas (contínuas e discretas) (OLIVEIRA, 2009, p. 92). 
O que sabemos do mundo empírico, em grande medida, deve-se a esse pensar puro que garantiu as condições a priori para adentrarmos nas coisas. Mas ao advogar em defesa do pensamento puro, mesmo na sua radicalidade mais extraordinária, não nego o mundo e as coisas, ao contrário, é necessário um pensamento sem o mundo, assim como é necessário que outros ou o mesmo pensador, acessem o mundo a partir deste pensar, num certo momento posterior.

$\mathrm{Na}$ lógica geral, portanto, a parte que deve perfazer a doutrina pura da razão precisa ser separada completamente daquela que perfaz a lógica aplicada (embora sempre geral). Somente a primeira é propriamente ciência, não obstante breve e árida como requer a apresentação escolástica de uma doutrina elementar do entendimento. Nesta, os lógicos tem sempre que ter presente duas regras:

1 Como lógica geral, abstrai de todo conteúdo do conhecimento do entendimento, bem como da diversidade dos seus objetos, não se ocupando senão com a simples forma do pensamento.

2 Como lógica pura, não possui nenhum princípio empírico, por conseguinte não tira nada (como as vezes se estava persuadido) da Psicologia, a qual portanto não possui nenhuma influencia sobre o cânone do entendimento. É uma doutrina demonstrada, e tudo nela precisa ser certo de modo inteiramente a priori. (KANT, 1781, p. 93).

Leibniz ambicionava elaborar uma linguagem totalmente formal, isto é, uma linguagem de símbolos que fossem capazes de traduzir os eventos do mundo de maneira límpida, original e certeira. No seu Livro Terceiro, Palavras, dos Novos Ensaios Sobre o Entendimento Humano, Leibniz faz uma investigação como a buscar a origem das línguas faladas, de como são semelhantes alguns vocábulos em línguas diferentes, de como sons de palavras assemelham-se aos eventos presentes na natureza, de como o som da água ou o som de animais poderiam ter levado o homem a produção de um determinado fonema para uma palavra específica. Mas, é curioso que ao longo do texto, o tempo todo se torna lúcido uma desconfiança com relação às ideias, as palavras e o mundo. Sua investigação almeja chegar às línguas originais que sem terem sofrido grandes mudanças acessariam o real de forma mais verdadeira. Porque,

o hebraico ou o árabe são línguas que mais se aproximam da primitiva, ela deve estar no mínimo bem alterada, e parece que o teutônico guardou mais do natural, [...] do adâmico: pois se possuíssemos a língua primitiva em sua pureza, ou pelo menos suficientemente conservada para ser reconhecível, seria necessário que nela aparecessem as razões das conexões, quer de ordem física, quer de uma instituição arbitrária, sábia e digna do primeiro autor. (LEIBNIZ, 1765, p. 270.) 
Pois, ao longo da construção das línguas, muito se criou, se inventou, ora por causa de necessidades, a comunicação do grupo para a sobrevivência numa determinada realidade biológico-geo-espacial-sócio-política, dada; ora, por noções advindas de demandas já totalmente sociais no sentido, por exemplo, do como criminosos, transformam a língua usando de recursos para não serem entendidos, ou hoje, com a Revolução $\mathrm{Hi}$-tech, do emprego quase habitual de terminologias do ciberespaço que estão em inglês em língua portuguesa como se fossem propriamente lusitanas. Disto se conclui que a língua que operamos no real é incrivelmente ambígua e, apesar de muito útil, ela tem limites quase intransponíveis. Todavia, Leibniz aponta para a geometria e a aritmética como noções mais precisas, diz:

[...], seria difícil estabelecer com precisão os limites entre o azul e o verde, e em geral discernir as cores muito próximas, ao passo que podemos possuir noções precisas dos termos dos quais nos servimos na aritmética e na geometria. (LEIBNIZ, 1765, p. 287).

Frege em Sobre o Sentido e a Referência alude à questão incômoda, questionando se há uma igualdade na relação entre os nomes e sinais, e os objetos do mundo ou se trata de um problema, a saber, o de saber se há igualdade entre as palavras e as coisas. Ou esta aparente coincidência é um engodo ao qual deveríamos nos atentar? Para ele,

$a=a$ e $a=b$ são, evidentemente, sentenças de valor cognitivo diferentes, pois $a=a$ sustenta-se $a$ priori e, segundo Kant, deve ser denominada de analítica, enquanto que sentenças da forma $a=b$ contêm, frequentemente, extensões muito valiosas de nosso conhecimento, e nem sempre podem ser estabelecidas a priori. (FREGE, 1892, p. 129).

Frege foi um filósofo contemporâneo, dedicado à filosofia da matemática e às questões da linguagem. Para ele o mundo e a linguagem não são coincidentes e, portanto, seria de emergencial importância criar-se uma linguagem artificial à qual ao referir-se ao mundo desvelasse o mundo ou, se Kant estiver correto, o fenômeno que nos é factível o acesso; uma linguagem formal capaz de revelar o mundo sem os condicionamentos psicológicos morais espalhados nas linguagens naturais. Assim, a matemática pura, principalmente, e a lógica, constituir-se-iam linguagens formais capazes de elencar as categorias a priori. O problema encontrado por ele no século XIX deveu-se ao fato de que a ferramenta lógica não tinha sofrido grandes progressos. Basicamente o que se tinha de lógica era a Lógica Silogística. A missão a qual assumiu fora desenvolver um Projeto Logicista, que culminará em Russel e Whitehead. 
A Tradição Analítica, talvez destoando um pouco de outras tradições filosóficas, entende que o conhecimento sofre um progresso, que partimos de um não-entendimento das coisas para um entendimento, que os pressupostos teóricos e lógicos avançam no sentido de esclarecer e desvelar o real. “[...] o problema central da Epistemologia sempre foi e continua a ser o problema do aumento do saber. O aumento do saber pode ser mais bem analisado se analisarmos o aumento do conhecimento científico." (POPPER, 1972, p. 536). A verdade escondida por trás das coisas é capaz de emergir, não como um absoluto inquestionável (isto seria dogma religioso), mas como alguma coisa que não nos era inteligível e passa ao campo da inteligência humana. Para os lógicos, se conseguirmos a ferramenta adequada, bastaria encaixá-la no mundo para rodar os parafusos do real e abrir a tampa que mostra a multiplicidade de peças, que exigem, por sua vez, outra multiplicidade de ferramentas, do motor da vida. É inegável que haja um progresso da lógica de Aristóteles até, por exemplo, a Lógica Modal de Kripke.

A lógica formal desenvolvida por Frege não teve pleno sucesso no sentido de conseguir finalizar uma ferramenta capaz de abarcar a totalidade do mundo numa codificação semântica perfeita. Porém, o esforço epistemológico por si, é louvável e merece sua inscrição na História da Filosofia.

No entanto, o insucesso constatado nesse programa não caracteriza uma falta de importância para esta escola, principalmente pela influência que o Principia tem na história da Matemática e pelo tratamento lógico que possibilitou o desenvolvimento da Lógica Matemática Moderna. Isso ocorreu especialmente pela introdução da simbologia dos quantificadores $\forall$ (para todo) $\exists$ (existe), criada por Frege em sua obra que objetivava formalizar as regras de demonstração, iniciando com regras elementares simples sobre as quais não houvesse dúvidas, a qual revolucionou a lógica, pois proporcionou o desenvolvimento do cálculo de predicados (ou lógica de predicados). (BATISTELA, BICUDO, LAZARI, 2017, p. 200).

Preocupado com os problemas da linguagem, queria dar fundamentação matemática a lógica, produzir fundamentos sólidos, angariar um método axiomático. Somente a geometria detinha uma base axiomática na qual dali se pudesse tudo derivar. A geometria euclidiana recorria à intuição e sendo totalmente a priori, se resolvia nela mesma. Diante deste formalismo característico da matemática, Frege pensou uma coleção de símbolos (matemática na lógica) que não continham nada do mundo. A matemática é inteiramente formalizada com propriedades lógicas, está dentro da linguagem, as verdades matemáticas são derivadas das verdades lógicas. Ora, se as afirmações 
matemáticas tem uma exatidão axiológica porque tem como substrato definições consistentes formalizadas pela lógica, então uma linguagem completamente artificial derivada da lógica consubstanciaria um mecanismo não ambíguo para nos referir às coisas. Todavia, é digno de nota na nossa defesa de um pensamento matemático puro que não importa, num primeiro momento, se esta linguagem acessa ou se preocupa em acessar o real ou não, encapsulada em seu alvéolo sistemático tem que se constituir enquanto tal, sem o mundo e sua corrupção, para ser pura. Não há aqui uma oposição a um naturalismo matemático como em Leifer (2014) que defende que não é a Física que é matemática, mas a matemática que é Física. O problema estrutural colocado é não reduzir a matemática a um aparelho conceitual subserviente aos outros saberes ou a realidade, como se existisse na condição de escrava da utilidade. Outrossim, os usos, os diálogos, as contribuições das ciências são profícuas à matemática como no Sexto Problema de Hilbert 1900 (apud da Costa 1987, p.189), que trata dos axiomas da física (HIFUME, 2003, p.72).

Se a geometria deve servir de modelo para o tratamento dos axiomas da física, convém que se tente, primeiramente, por meio de pequeno número de axiomas, delimitar uma classe, tão extensa quanto possível, de fenômenos físicos, e, então, pela adição de novos axiomas, chegar-se, gradualmente, às teorias mais especiais. (...) O matemático terá de levar em conta, não apenas as teorias próximas da realidade, mas, também, como na geometria, todas as teorias logicamente possíveis. Ele precisa estar alerta para obter um inventário completo de todas as conclusões que são consequências do sistema de axiomas assumido. (Idem.)

Depois, o sistema pronto, muitos enigmas já propostos e solucionados, no sistema, com suas regras, considerando seus limites, se pode dar uso empírico a esta linguagem formal. Um uso que ao encaixar a ferramenta a peça do mundo, utilize as regras da ferramenta para não se corromper deveras pelas regras do mundo. Pois as regras linguísticas de acesso ao mundo (linguagens naturais) distorcem-no falsificando-o, porque nos perdemos nos labirintos da linguagem criando problemas que não existem.

\section{Observe:}

$$
\begin{aligned}
& \neg \rightarrow \text { "não é verdade que..." } \\
& \wedge \rightarrow \text { conjunção "e" } \\
& \text { v } \rightarrow \text { conjunção "ou" }
\end{aligned}
$$


$\rightarrow \mathrm{C} \rightarrow$ implicação material "se..."

$\leftarrow \rightarrow$ bi-implicação material "se e somente se..."

Se a linguagem pudesse ser reduzida esta simbolização, se deduziria imediatamente que se as sentenças estão simbolizadas, logo os argumentos também podem ser formalizados e se anularia as ambiguidades. Entretanto, o real tem na sua realidade a própria ambiguidade, portanto a pretensão de Leibniz de uma linguagem totalmente formal é impossível, pois a simbolização do fenômeno se adequaria perfeitamente se nada de caótico habitasse o movimento das coisas, mas um imponderável insistente sempre aparece para anarquizar o real retirando-lhe toda e qualquer causalidade anteriormente definida. Outrossim, apesar destas incertezas próprias da angústia da vida, é plenamente aplicável diversos elementos das linguagens formais no entendimento do mundo, não para plenificar o mundo de substância, mas para significá-lo pragmaticamente.

Certamente, a cada expressão que pertença a um sistema perfeito de sinais deveria corresponder um sentido determinado; as linguagens naturais, porém, raramente satisfazem a essa exigência e deve-se ficar satisfeito se a mesma palavra, no mesmo contexto, sempre tiver o mesmo sentido (FREGE, 1892, p. 133).

A relação entre signo e objeto é puramente arbitrária. Concordamos que "Sócrates é filósofo" por mero pragmatismo. Podemos e, de fato, construímos narrativas, cavamos cemitérios, aludimos a livros, transmitimos os saberes e costumes, de uma geração a outra, pela educação, elaboramos sistemas lógicos, científicos, fundamos a cultura como baluarte da imortalidade dos homens, mas nada disto nos garante com toda certeza, sem que nada haja mais a ser discutido, que se falasse de uma vez por todas, que se desse a última palavra, que sim: "Sócrates é filósofo". Ora, se Sócrates "é”, alguma coisa, então, refiro-me ao mestre de Platão, ao gerente do banco ou ao grande driblador do time do Botafogo? "É", se refere a um tempo histórico (o presente), e também a uma condição de ser que só pode ser daquela maneira e não de outra, logo precisaríamos de um sistema lógico mais sofisticado para julgar a falsidade ou a verdade das sentenças com maior rigor ou certeza, o problema posto não se resolve lendo a proposição e verificando no real a sua validade, é mais complexo! Repito: homem e mundo não são triviais! Se o mundo detém sua particular linguagem com suas regras, e as linguagens naturais elaboram seus 
símbolos para buscar a linguagem do mundo numa forma de entendimento, e os matemáticos e lógicos tem a deles, uma linguagem completamente outra, fechada em si mesma, então não há crime algum a acusar aos matemáticos e lógicos de estarem num lugar sem o mundo, se o mundo esta em outro lugar sem os lógicos, numa distancia profundamente longínqua, e qualquer conexão entre os diversos mundos seria elementarmente pragmática! Mas, ainda, esta pragmática que é uma tentativa de acessar o mundo pelos signos se vislumbra profícua se, se parte de uma linguagem completamente artificial. Ora, "se outras ideias fossem examinadas segundo o método comum aos matemáticos, conduziriam os nossos pensamentos mais longe do que poderíamos talvez imaginar." (LEIBNIZ, 1765, p. 456).

Ao menos os lógicos são humildes para colocar seus puzzles e verificar os limites de seu sistema. De saída, se são puzzles, testam a validade de seus mecanismos e elaboram premissas organizando metodologicamente a forma como o pensamento pode acessar o mundo, tentando evitar erros levianos e infantis, projetando burlar a promiscuidade do mundo e das linguagens naturais. É de sábia inteligência, antes de começar o jogo, escrever as regras, ou seja, elaborar os conceitos, se dedicar ao cuidado de diminuir as ambiguidades dos postulados, esclarecer como se deduzirá as evoluções. Definido, antecipadamente, as variáveis, imaginando quais outras poderiam surgir no exercício da investigação, verificando probabilidades de erros, acertos, incertezas diversas; enfim, organizando as peças do tabuleiro e sabendo as regras de antemão, poder-se-ia então avançar na descoberta do real. Os puzzles de linguagem podem ser de três tipos e constituem regras do jogo: 1: apresentam Valores de Verdade; 2: obedecem o Princípio de Composicionalidade e 3: seguem o Princípio de Substitutividade.

Uma sentença passa por um julgamento onde se lhe é possível atribuir Valores de Verdade, ou seja, ela pode ser Falsa ou Verdadeira. Ao se atribuir tais valores a sentença, recorremos a informações que revelam-se no real. Logo, existe sentido e referência de uma sentença. Assim, para Frege “Sócrates é filósofo!” tem um sentido (Sinn) e, também, uma referência (Bedeutung). Tem um sentido porque todos nós, partícipes de uma comunidade linguística, conhecedores das regras estruturais desta língua, atribuímos significado a cada uma das palavras da sentença fundando um sentido geral por Princípio de Composicionalidade. Mas o sentido, somente, não nos autoriza a julgar a sentença nem como Falsa, nem como Verdadeira, porque o julgamento da proposição passa pela análise 
de seu referente no mundo (Princípio da Substitutividade). Para a sentença acima podese indicar um Valor de Verdade Verdadeiro se considerarmos que Sócrates foi mestre de Platão e Xenofonte e que graças a seus discípulos houve um registro pormenorizado de alguns dos diálogos, além dos debates dos historiadores que com suas pistas, efetivamente, argumentam que, sim, Sócrates existiu e foi filósofo e vivia por Atenas na época Clássica. A questão posta é: sentido e referência não são coincidentes. A afirmativa “Sócrates é filósofo!” não é trivial, há que se debruçar sobre o mundo e desnudá-lo.

O problema é tão espinhoso que expressões como, "Raskolnikov é um assassino!" tem sentido, mas não tem referência. Frege indaga: "É possível que uma sentença como um todo tenha tão-somente um sentido, mas nenhuma referência?" (FREGE, 1892, p. 137). Ou seja, Raskolnikov não tem referência no mundo empírico porque é uma personagem do livro Crime e Castigo de Dostoiévski. Por mais que todos os dias se lembrem pelos noticiários que assassinos cruéis estão as soltas por aí, e sabe-se lá Deus o que se passa psicologicamente com este sujeito, que seja a mesma dor de Raskolnikov, o mesmo sofrimento de se ver condenado por sua própria miséria existencial, por sua mesquinhez, sordidez e vilania; nenhum destes assassinos por mais semelhantes que sejam a Raskolnikov constitui referência no real que nos permita julgar a sentença colocada como Falsa ou Verdadeira. Assim, há sentido, sem referência. As artes tem sentido, porém são vazias de referência. Assim como,

A sentença "Ulisses profundamente adormecido foi desembarcado em Ítaca" tem, obviamente, um sentido. Mas, assim como é duvidoso que o nome "Ulisses", que aí ocorre, tenha uma referência, assim também é duvidoso que a sentença inteira tenha uma. (FREGE, 1892, p. 137).

\section{Os cinco postulados de Euclides}

Euclides definiu os objetos da geometria os quais se desejava estudar suas propriedades, como: ponto, reta, círculo, triângulo, retas paralelas, etc. A partir daí afirmou cinco noções comuns consideradas autoevidentes que sustentariam o estudo destes objetos. São elas:

1 - Coisas iguais a uma mesma coisa são também iguais.

2 - Se iguais são adicionados a iguais, os totais obtidos são iguais.

3 - Se iguais são subtraídos de iguais, os totais obtidos são iguais.

4 - Coisas que coincidem uma com a outra são iguais. 
5 - O todo é maior do que qualquer uma de suas partes.

Considerando estes pressupostos iniciais, lançou mão de cinco postulados os quais não seria necessária comprovação empírica alguma, já que são axiomáticos:

Postulado 1 - Pode-se traçar uma (única) reta ligando quaisquer dois pontos.

Postulado 2 - Pode-se continuar (de uma única maneira) qualquer reta finita continuamente em uma reta.

Postulado 3 - Pode-se traçar um círculo com qualquer centro e com qualquer raio.

Postulado 4 - Todos os ângulos retos são iguais.

Postulado 5 - Se uma reta, ao cortar outras duas, forma ângulos internos, no mesmo lado, cuja soma é menor do que dois ângulos retos, então estas duas retas encontrar-se-ão no lado onde estão os ângulos cuja soma é menor do que dois ângulos retos.

O que pretendia Euclides era com poucas proposições derivar todo o resto. Tendo poucos conceitos, e conceitos bem simples, se chegaria a todo o resto. $\mathrm{O}$ axioma sugere precisamente isto, se afirmar algo de tal maneira intuitivo, que não haja necessidade de dar explicações adicionais, sendo dito com a proposição o que é totalmente a priori. Afirmações tais, que sendo tão rigorosas na sua simplicidade, sejam verdadeiras sem precisar ir ao mundo para justificar-se. São tautologias, vazias de significado, pois não se referem ao mundo, estão presas no seu próprio sistema linguístico, são puras.

Frege argumentava que o sentido pode ter ou não um referente no mundo e que, se é possível dar Valores de Verdade à sentença avaliando o referente no mundo. Ou seja, a partir da lógica, uma linguagem artificial, se acessaria o mundo atribuindo-lhe significado. Entretanto, tais valores de verdade verdadeiros estão longe de alcançar a profundidade de um axioma e os aceitamos como significação de mundo por necessidade pragmática.

O sentido de um nome próprio é apreendido por todos que estejam suficientemente familiarizados com a linguagem ou com a totalidade de designações a que o nome próprio pertence; isto, porém, só de maneira parcial elucida a referência do nome, caso ele tenha uma. Para um conhecimento total da referência, exigirse-ia que fôssemos capazes de dizer, de imediato, para cada sentido dado pertence ou não a essa referência. Isto, porém, nunca conseguiremos fazer (FREGE, 1892, p. 132).

É desta dificuldade de averiguar o mundo com total certeza que surge o milenar debate filosófico. Nós não temos absolutamente nenhuma certeza sobre o mundo, ele nos é impossível, ou sempre superficial, porque a travessia do homem em direção ao 
entendimento eterno das coisas só acontece por meio da linguagem, ambígua em si mesma. Porém, ainda que bastantes conscientes dos percalços no processo de produção do conhecimento, não desistimos, e esta persistência, curiosa e frustrante, nos surpreende com alguns achados espetaculares, a matemática pura tem a seriedade e a competência necessárias para afirmar axiomas, leis, teoremas, que se não são eternos, são duros o suficiente para atravessar os séculos como algo inquebrantável, indestrutível. Os postulados de Euclides tem este valor, durante 23 séculos, ninguém conseguiu contrapor, propor ou invalidar seus axiomas, o máximo que se conseguiu foi substituir uma formulação por outra. Pois, acreditava-se, "o modelo seria uma obra divina, uma verdade absoluta e eterna e que foi, apenas, descoberto pela razão" (ANDRADE, 2007, p. 07). Ora, o que detém o axioma que o torna tão poderoso e o que estudam os matemáticos para terem tanta certeza das coisas de forma a deixarem o mundo completamente distante de suas reflexões? Mas, mais ainda, como podem estas meditações (cálculos, teoremas, postulados, axiomas, enfim...), como pode a matemática estar debruçada sobre si mesma, encapsulada na sua redoma, afirmando suas sentenças, indiferente ao mundo e, ao mesmo tempo, referir-se ao mundo, dar soluções criativas aos problemas cotidianos do homem, inventar máquinas, propor curas médicas a partir de enigmas que a química farmacêutica não solucionaria sozinha, mas que tendo a matemática como aliada avança a passos largos, como pode a matemática aplicada recuperar da solidão das verdades eternas dos axiomas, um lugar completamente outro, os pedregulhos conceituais que cimentam a conexão exata entre a linguagem artificial e o mundo?

A novidade da matemática deve-se a sua estratégia, nem um pouco ingênua, de fugir às ciladas da linguagem e operar num sistema sem ambiguidades. É importante salientar que na matemática verifica-se uma série de limitações e crises, como a crise da incompletude dos sistemas axiomáticos de Gödel e a crise na teoria dos conjuntos de Russel.

A consistência se firmou como um problema para a comunidade matemática no século XIX, no período de grande expansão e intensificação da pesquisa em Matemática. Nagel e Newman (1973) explicam que a conclusão da impossibilidade lógica da solução dos problemas clássicos da Antiguidade produziu investigações profundas sobre a natureza do número, definições rigorosas para conjuntos numéricos, chegando a fundar um novo ramo da Matemática, como um valioso subproduto dessas demonstrações, qual seja, o campo da análise. Além disso, o episódio protagonizado por Carl Friedrich Gauss (17771855), János Bolyai (1802-1860), Nikolai Lobachevsky (1792-1856) e

Georg Friedrich Bernhard Riemann (1826-1866) em torno da criação das 
geometrias não-euclidianas foi crucial junto a esse processo de abstração a que a Matemática estava se propondo. Resultados fecundos são obtidos quando se substitui o quinto postulado de Euclides por versões de suas negações nos casos dos surgimentos das geometrias não-euclidianas, e estes "solaparam a crença tradicional, sustentada pela geometria euclidiana, de que os axiomas da geometria poderiam ser estabelecidos por sua aparente autoevidência". (Nagel \& Newman, 1973, p.19). (BATISTELA; BICUDO; LAZARI, 2017, p. 203).

As antinomias, isto é, os paradoxos matemáticos que deflagraram a crise primordial nos consistentes sistemas lógicos, nos séculos XIX e XX, são assertivas que, não se é possível atribuir valores de verdade ou falsidade, e que, portanto, são contraditórias. Russel abriu a crise para demonstrar as falhas lógicas do sistema de Frege a partir do paradoxo que recebeu o seu próprio nome. O conjunto de todos os conjuntos não pode ser conjunto de si mesmo.

O paradoxo acontece, na teoria dos conjuntos, se aceitarmos o seguinte axioma: "existe um conjunto de todos os conjuntos que obedecem a uma determinada propriedade", e adotarmos como propriedade o que segue: "o conjunto de todos os conjuntos que não são elementos de si próprios". Agora, assumindo o axioma, analisemos um conjunto que obedece à propriedade mencionada. Portanto, seja $\mathrm{R}$ um conjunto definido pela propriedade anterior e expresso matematicamente da maneira que segue: $R=\{x \mid x \notin x\}$, isto é, se $x \in R \rightarrow x \notin x$; e, se $x \notin R \rightarrow x \in x$. Como $\mathrm{x}$ é uma variável qualquer podemos fazer, sem perda de generalidade, $x=R$ e assim, estarmos numa situação paradoxal de natureza lógica, ou seja, $R$ $\in R \rightarrow R \notin R$; e, se $R \notin R \rightarrow R \in R$. (MONTEIRO; MONDINI, 2020, p. 14)

Cantor apresenta aspecto semelhante quando anuncia que o conjunto universal $U$ compõe todos os conjuntos. Os conjuntos da totalidade que configura o U são menores que $U$, o problema é que as partes do U universal são maiores que o $U$, isto porque $U$ não pode ser conjunto de si mesmo, mas somente de outro conjunto que ultrapasse o universal. Então o conjunto U só poderia ser enquanto não-conjunto, e se ele é não-conjunto não pode agrupar todos os conjuntos porque não é conjunto de nada. Assim, “[...] quando consideramos o conjunto $\mathrm{P}(\mathrm{U})$ (conjunto das partes de $\mathrm{U}$ ), concluímos, pela definição, que $P(U)>U$, o que contradiz a hipótese de existir um conjunto de todos os conjuntos (ÁVILA, 2000, p. 8).” (MONTEIRO; MONDINI, 2020, p. 17). Esse modelo da crise da teoria dos conjuntos desembocará no paradoxo do barbeiro. Se o único barbeiro da cidade só pode fazer a barba de quem não se barbeia, então quem fará a barba do barbeiro? Se ele fizer a barba não esta no conjunto dos que não se barbeiam, logo não poderia se barbear, ora, mas é ele que barbeia quem não se barbeia e ele é também quem não se 
barbeia! Por outro lado, se, se barbear, não poderá fazer a barba de si mesmo porque esta no conjunto de quem se barbeia e não precisa dos serviços do único barbeiro.

O paradoxo ocorre porque o problema do tempo aparece na interface dos conjuntos. Uma solução para o paradoxo do barbeiro seria retirar o tempo da intersecção dos conjuntos, porém o universo signo intelectual humano somente é na medida do tempo, ou seja, a possibilidade de retirar o tempo da análise é completamente inverossímil diante da realidade dada no tempo-espaço, permanecendo o imbróglio. E o próprio tempo com o seu despotismo causalista determina por sua objetividade operacional, os paradoxos, que não são apenas matemáticos. Outra solução seria desenvolver conjuntos menores para conjuntos maiores numa escala de um pra um até o infinito evitando, já no limite do infinito, atribuir a um conjunto $U$ universal o anseio de abarcar todos os conjuntos independentemente de escala. $\mathrm{Na}$ medida em que o conjunto menor cabe no maior obedecendo a um limite razoável, até o infinito, se mantém uma margem de controle capaz de impedir a deflagração abrupta das antinomias. Mais uma vez o rigor matemático, mesmo no momento de sua crise mais crucial consegue estabelecer alguns indicativos de como o real, o homem, a filosofia e o conhecimento esbarram nas contradições. Curioso como mesmo a contradição operando de forma evidente, a matemática persevera numa dimensão mais tranquila da inteligência, pois se mune de um arsenal conceitual bastante sólido em seu planejamento. E quando o planejamento não dá conta do que escapa, outros recursos atuam numa espécie de transcriptase reversa, recriando e calculando a partir das dimensões do caos e do imponderável.

Dessa forma, Zermelo teve que optar pela impossibilidade de se considerar a definição de conjunto irrestritamente, notadamente no caso "do conjunto de todos os conjuntos", ou ainda o "conjunto de todos os conjuntos que não pertencem a si mesmos". Zermelo percebeu a possibilidade de criar novos conjuntos infinitos sempre a partir de outro infinito já existente. Exemplificando, a partir do conjunto dos naturais $\mathrm{N}$, podemos tomar dois pares $(a, b), b \neq 0$ e, a partir deles, obter os racionais Q. (MONTEIRO; MONDINI, 2020, p.18).

Ora, nas linguagens naturais se, se quiser denominar uma categoria universal e eterna que explique todas as coisas numa condição a priori, se lançará mão, por exemplo, da ideia de Deus enquanto uma potência ou força que estivessem para além da história na configuração espaço-tempo do universo conhecido pelos homens. Uma categoria problemática, porque depende de muitos aspectos, das crenças, de como essas crenças se processam numa religiosidade, e de como a religião é institucional ou não, e se está 
vinculada ao Estado e mais uma séria de outros elementos que não validam a hipótese como uma certeza. Por outro lado, a matemática lança mão de postulados, axiomas, não porque estes pudessem, efetivamente, ratificar uma verdade eterna, mas pelo menos consolidam verdades por um período mais longo, obedecendo a uma progressão, se sai do simples para o complexo, fundando paradigmas os quais determinam o que temos e de onde devemos caminhar. Não dá para ir às origens todas as vezes que se quiser aprender algo e desenvolvê-lo. A transmissão do conhecimento matemático é feita aos aprendizes de forma a inseri-los na linguagem apresentando os progressos alcançados e encorajando-os a irem mais.

Todavia, sem os axiomas e os teoremas já conhecidos, os matemáticos teriam muita dificuldade em avançar; pois nas longas consequências, é bom parar de tempos em tempos, e fazer por assim dizer colunas militares ao meio do caminho, que servirão também para os outros para marcá-los. Sem isso, estes longos caminhos serão demasiados incômodos e parecerão até confusos e obscuros, sem que possamos discernir neles nada, a não ser o lugar onde estamos. (LEIBNIZ, 1765, p. 422).

O quinto postulado de Euclides, por séculos a fio, significou um grande enigma para os matemáticos. A negação do postulado surgiu, primeiro, com a tentativa de sua comprovação com Giovanni Saccheri (1667 - 1773) que não supunha uma geometria que não fosse euclidiana. Depois surgiram János Bolyai, um húngaro, e um russo, Nicolai Lobaschevsky que, efetivamente, desenvolveram uma geometria não euclidiana.

A Geometria Hiperbólica atual só foi formalizada em 1832 por János Bolyai, que propôs que "Por um ponto fora de uma reta passa mais de uma reta paralela a ela". Nesse contexto, a soma das medidas dos ângulos internos de um triângulo é menor que $180^{\circ}$, ou seja, esta geometria nega a unicidade da reta paralela do $5^{\circ}$ postulado de Euclides. (SILVA, 2018, p. 21).

A questão levantada pelos matemáticos era de que o axioma de Euclides não constituía-se um postulado de verdade, não encontrava-se encapsulado em si mesmo, ou seja, a contestação sugeria que mais explicações precisavam ser desenvolvidas, mas por meio do mundo empírico. Supunham que o postulado fosse um teorema. O problema deuse porque, efetivamente, nada se encontrou no mundo que pudesse comprovar o axioma. Tanto tempo depois e o quinto postulado manteve-se. Entretanto, a negação do postulado, e negar não é invalidar, gerou outras geometrias, chamadas de geometrias nãoeuclidianas, como, por exemplo, a geometria hiperbólica, referida acima, a elíptica e a projetiva, para citar as principais, mas o campo ampliou-se significativamente a partir do 
século XIX. "Depois de Bolyai e Riemann, outras geometrias mais recentes têm surgido, como a Geometria Projetiva, a Geometria do Taxista e a Geometria do Fractal (MONTOITO, 2011).” (SILVA, 2018, p. 22). Se por um ponto fora da reta passa mais de uma reta paralela a ela, de outro modo, por um ponto fora da reta pode não passar nenhuma reta paralela a ela.

A Geometria Elíptica, publicada por Georg Bernhard Riemann em 1851, também nega o $5^{\circ}$ postulado de Euclides, mas com relação a existência da reta paralela: "Por um ponto fora de uma reta não passa reta paralela a ela". Nesta geometria, a soma das medidas dos ângulos internos de um triângulo é maior que dois ângulos retos. (Idem.)

Por fim, a geometria projetiva é uma não afirmação e uma não negação do $5^{\circ}$ postulado. Proveniente do contexto do Renascimento nas artes (séculos XIII, XIV e XV), emergiu de uma demanda específica, o desenvolvimento de noções de perspectiva para aproximar as telas e afrescos de imagens mais realísticas. Artistas realizaram o esforço de aproximar o debate das artes plásticas da matemática, angariando avanços consideráveis nas técnicas de pintura e expressão estética. "Então no início do século XIV, Duccio di Buoninsegna (1255-1319) foi um dos primeiros pintores a desenvolver uma técnica (ainda rudimentar) de perspectiva [...]." (SILVA, 2018, p. 23). Renomados artistas, profundamente conectados ao espírito de seu tempo, escreveram artigos para enriquecer o debate e produzir conhecimentos científicos capazes de explicar os fenômenos físicos, químicos, astronômicos, de modo criativo e objetivo. Esta dimensão do pensamento racional-científico, não estava desprendida das artes numa especialização das ciências aos moldes Iluministas. Artistas e cientistas (às vezes a mesma pessoa atuando em ambos os campos) comungavam dos mesmos saberes, produzindo-os e aplicando-os de acordo com suas necessidades.

Para Almeida (2007), houve uma importante mudança no desenvolvimento dessas técnicas quando Leonardo da Vinci (1452-1519) e Albrecht Dürer (1471-1528) começaram a escrever tratados que relacionavam a arte com a matemática, enfatizando a importância desta última para a pintura (SILVA, 2018, p. 24).

A geometria como ancoradouro seguro da realidade do mundo na sistemática do saber humano ainda não é suficiente, apesar de suas premissas sólidas. Se os aspectos autoevidentes do quinto postulado se sustentam como axioma, não como teorema, outrossim, sua aplicabilidade no mundo como referencial metaempírico não se justifica como ontologia da verdade porque o mundo das formas geométricas sofre distorção pelo posicionamento do olho humano com relação ao mundo objetivo. Por isso, a origem de

Perspectivas - Revista do Programa de Pós-Graduação em Filosofia da UFT - volume 5, n. 1 - 2020 
uma outra geometria no bojo desse grande debate. "A Geometria Projetiva vem então para mostrar que o mundo físico é diferente daquele que enxergamos com nossos olhos, pois nosso olhar é limitado e depende da posição em que nos encontramos." (SILVA, 2018 , p. 23). A geometria projetiva não nega a geometria euclidiana, apenas tem preocupações diferentes no que concerne a sua inventibilidade e aplicabilidade. Numa projeção os ângulos e comprimentos não são preservados redirecionando o foco da disputa para uma nova geometria, que não nega a primeira, nem a afirma como tal, pois o problema da soma dos ângulos internos das retas paralelas desaparece como propriedade estruturante do debate.

Para Stillwell (2010), a Geometria Projetiva trata da preservação de ponto e linha, as duas únicas coisas imutáveis dentro dessa Geometria. Como ângulos e comprimentos não são preservados em uma projeção, não se tem significado deles dentro dos estudos em Geometria Projetiva, simplificando assim a classificação de curvas. (SILVA, 2018, p. 23).

Não é intuito deste trabalho, fomentar um saudosismo de uma época que não vivemos, mas os Antigos tem um tino para coisas profundas. Poderíamos considerar que a geometria euclidiana perseverava por uma ontologia como anteprojeto de uma teoria fundamental que buscava os sólidos fundamentos do mundo pela razão pura de um entendimento absoluto. A geometria projetiva tem uma preocupação extremamente prática e louvável. Destarte, o desejo dos artistas renascentistas de uma técnica capaz de colocar profundidade no plano não partiu deveras do vazio, os fundamentos, assim como a discussão já estavam colocados por Euclides que, outros, querendo provar o "teorema", negá-lo, reafirmá-lo ou dizê-lo de outra forma, denunciavam desde Proclo (séc. V) passando pelos árabes medievais como Omar al-Khayyam (1048 - 1131) e Nasir ad-Din al-Tusi (1201 - 1274), a solidez epistemológica da razão matemática.

Enquanto a Geometria Euclidiana se preocupa com o mundo em que vivemos, a Geometria Projetiva lida com o mundo que vemos. Na prática, os trilhos de trem não são retas paralelas, mas retas que se encontram no horizonte, no infinito. Essa é uma das características marcantes da Geometria Projetiva, duas retas quaisquer sempre se intersectam (SILVA, 2018, p. 24).

E mais, todas as tentativas de provar o postulado foram fracassadas, isto porque no fim das contas verificou-se que os recursos utilizados para tal empreitada não se sustentavam, pois eram fundamentos do próprio axioma colocado por Euclides. Ou seja, 
o quinto postulado demonstrou ser, por mais de dois milênios, a cápsula inquebrantável do a priori na medida em que a verdade autoevidente de sua sentença é irrefutável porque até agora nada conseguiu penetrar a membrana semântica de seu próprio sistema interno. O quinto postulado de Euclides é, de um modo que lhe é impossível não-ser. Todavia, isto que começa e acaba em si mesmo como uma sublime formulação da razão pura ampliou o debate para outras dimensões: teóricas, abstratas, pragmáticas, utilitárias, pedagógicas.

Por 2000 anos, vários matemáticos tentaram provar o $5^{\circ}$ postulado, encarando-o como um teorema a partir dos restantes nove axiomas e postulados $\mathrm{e}$ isso gerou um imenso alcance $\mathrm{e}$ importante desenvolvimento da matemática moderna, como nos traz Eves (2011). Foram muitas demonstrações do Postulado das Paralelas, porém descobria-se posteriormente que cada um tinha como base uma suposição equivalente a ele próprio (SILVA, 2018, p. 20).

O valor da matemática, além da sua capacidade engenhosa de afirmar postulados, é conhecer o mundo profundamente, como se o universo fosse matemático, como se o grande mago da Origem ao lançar as esferas da criação tivesse determinado uma ontologia da physis numa cosmologia das formas e dos cálculos. O mundo que é possível ao homem acessar utiliza na forma pura ou aplicada os fundamentos da matemática. Se o universo em si mesmo é matemático ou se por conhecermos a matemática, primeiro, organizamos os mundos, arbitrariamente, segundo as suas regras estruturais, a questão mais premente que surge, todavia, é: não existe universo sem a matemática porque não existe História dos Homens sem a História da Matemática. A matemática é tão (A)antiga quanto o homem. A natureza é matemática, a música é matemática, a poesia é matemática, as pinturas, as construções são matemáticas. E mesmo quando a matemática mergulha em suas crises, também é capaz de afirmar matematicamente a impossibilidade matemática do conjunto U, por exemplo. Nem todos os homens conhecem Shakespeare ou leram uma linha de Thomas Mann, ou ouviram Tchaikovski, ou compreendem, mesmo que preliminarmente, a anatomia e a fisiologia das organelas de uma célula, porém, todas as pessoas, em todos os lugares do mundo, sem nenhuma exceção, tem algum conhecimento de matemática porque se não o tivessem estariam fadados a morrer por incapacidade de lidar coerentemente com as adversidades do mundo na luta pela sobrevivência da espécie humana. Porque a matemática é um componente abstrato e teórico, e ao mesmo tempo prático e intuitivo. Ora, as mais diversificadas culturas humanas aprenderam a construir suas casas, a se locomover pela observação das estrelas, a calcular valores monetários

Perspectivas - Revista do Programa de Pós-Graduação em Filosofia da UFT - volume 5, n. 1 - 2020 
para a atividade de trocas de materiais, de instrumentos, de alimentos. Desenvolveram a agricultura, testaram mecanismos e quantidades de matéria prima capazes de medir e controlar o poder do fogo, criaram para os momentos de ócio, descanso e confraternização, jogos dos mais variados, profundamente matemáticos e divertidos, todas essas culturas fizeram uso da matemática de um modo que sugere, talvez, uma certa imanência do ser da matemática ao ser do homem, como se essa habilidade fosse tão humana quanto o seu próprio ato de caminhar.

\section{Considerações finais}

Nossa preocupação inicial de que se seria possível uma linguagem menos ambígua capaz de afirmar verdades de forma mais duradoura atravessou grandes expoentes do pensamento ocidental. Percorremos o seguinte caminho: passando por Kant trouxemos a questão principal de a Crítica da Razão Pura de se é possível os juízos sintéticos a priori, e verificamos que o pensador de Königsberg acreditava que deles se deveria partir em direção ao mundo empírico; já Leibniz sustentava a ideia de uma linguagem completamente artificial e que a matemática possuía esses pressupostos axiomáticos; e, por fim, buscamos os argumentos lógicos de Frege sobre Sentido e Referência e mais uma vez aludimos a sua desconfiança com relação às linguagens naturais e comentamos sobre seu projeto logicista.

O percurso Kant-Leibniz-Frege estrutura-se no insistente esforço intelectual humano de obter uma fagulha, que seja, no sentido de estabelecer um conhecimento totalmente a priori. Porque todo conhecimento já é conhecimento de um homem completamente impregnado do mundo e da sua forma de inventar o mundo. O pressuposto do saber como uma torrente lívida do homem na sua condição mais genuína, demasiado humana, não é menor e indigna, mas se houver na intelecção cognitiva um acesso ao ente das coisas pela razão pura, valeria a pena a empresa. Todavia, o projeto deles demonstrouse frágil e desmoronou na própria dureza do mundo que rebelde na sua irreverência não se submete aos desejos da razão teleológica humana. $O$ mundo sem razão preenche de angústia o homem culto e é desta dor que todos eles continuam a sua marcha. Talvez um pouco tristes por seus esforços em vão, encontram um pouco de alegria quando descobrem moléculas borbulhantes de verdades autoevidentes na matemática. Os filósofos precisam dialogar mais com os saberes matemáticos na tentativa de superar a 
quimera do sentimento de impotência epistemológica com relação ao todo para alavancar suas premissas a partir de uma compreensão não binária da realidade, porque a Tradição Analítica não esta no campo oposto da Tradição Continental como a criar rivalidades intransponíveis. Da crise da matemática produziu-se mais coisas, instigou-se mais ações, promoveu-se mais amizades. Poderíamos aprender mais com os matemáticos quando da angústia de seu não saber, continuam altivos, na sua jornada paciente na formulação das regras de seu jogo conceitual, que é, desde sempre, e absolutamente, afirmação vigorosa da vida.

Percorrendo este trajeto queríamos advogar pela causa matemática, de que sua investigação pura é necessária nestas suas condições mesmas, isto é, sem o mundo. Conseguimos, ao final, argumentar a partir dos postulados de Euclides sobre geometria, que seus axiomas são bem mais duradouros que as máximas preconizadas por filósofos, teólogos, cientistas, saberes em muito mergulhados no mundo empírico. Toda esta exposição, além da defesa do objetivo central, trás num segundo plano, como condição sine qua non, a defesa também de uma razão pura fortemente consolidada na lógica. Os pressupostos lógicos são imprescindíveis à filosofia, assim como à Tradição Analítica, e, portanto, ambas tem um papel preponderante na produção do conhecimento. $\mathrm{O}$ avanço da lógica pode contribuir bastante na leitura dos pensadores da Tradição Continental.

\section{Referências bibliográficas}

ABE, Jair Minoro. Verdade pragmática. Estudos Avançados, 12(5), 1991.

ANDRADE, Plácido F. A. Introdução à Geometria hiperbólica plana, o disco de Poincaré; Texto impresso, UFC (2006).

ÁVILA, G. Cantor e a teoria dos conjuntos. Revista do Professor de Matemática, São Paulo, v. 43. 2000. p. 6-14. Disponível em:

http://www.educadores.diaadia.pr.gov.br/arquivos/File/2010/veiculos_de_comunicacao/ RPM/RPM 43/RPM43_02.PDF. Acesso em dez. de 2019.

BATISTELA, Rosemeire de Fatima; BICUDO, Maria Aparecida Viggiani; LAZARI, Henrique. O Cenário do Surgimento e o Impacto do Teorema da Incompletude de Gödel na Matemática. JIEEM v.10, n.3, p. 198-207, 2017.

DA COSTA, N.C.A. ([1987] 1992) O Conceito de Estrutura em Ciência. Boletim da Sociedade Paranaense de Matemática, 2a. série, v. 8. In: Doria \& Katz, 1992.

EUCLIDES. Os Elementos. Tradução de Irineu Bicudo. São Paulo: UNESP, 2009. 
EVES, H. Introdução à história da matemática. Tradução de Hygino Domingues.

Campinas: Editora da Unicamp, 2011

FREGE, Gottlob. Sobre o Sentido e a Referência, [S.I.] 1892.

GÖDEL, Kurt. O Teorema de Gödel e a Hipótese do Contínuo. Fundação Calouste Gulbenkian, Lisboa, 1979.

HIFUME, Carlos. Uma teoria da verdade pragmática: a quase-verdade de Newton C.A. da Costa. Campinas: SP, 2003.

KANT, Immanuel. A Crítica da Razão Pura. São Paulo: Nova Cultural, 1999.

LEIBNIZ, Gottfried Wilhem. Novos Ensaios Sobre o Entendimento Humano. São Paulo: Nova Cultural, 1996.

LEIFER, Matthew Saul. Is the Quantum State Real? An Extended Review of $\Psi$-ontology Theorems. Quanta, DOI: 10.12743, volume 3, Issue 1, page 67-155, November 2014.

MLODINOW, L. A janela de Euclides. São Paulo: Geração Editorial, 2005.

MONTEIRO, Gisele de Lourdes; MONDINI, Fabiane. Sobre a Inconsistência Lógica das Antinomias. Educação Matemática em Revista, Brasília, v. 25, n. 67, p.11-20, abr./jun. 2020.

OLIVEIRA, Érico Andrade M. de. Pragmatismo e o caráter abstrato do objeto matemático nas Regulae ad Directionem Ingenii. Cad. Hist. Fil. Ci., Campinas, Série 3, v. 19, n. 1, p. 89-114, jan.-jun. 2009.

PEREIRA, Renato machado. Concepção Semântica da Verdade Segundo Alfred Tarski. São Carlos: UFSCAR, 2009.

PETRY, Luís Carlos (1998). Do porque nada funciona. In: Psicanálise e Sintoma Social II, Mário Fleig (org.). São Leopoldo. Editora UNISINOS. p. 257-291. IBNS: 8585580593.

POPPER, Karl R. A lógica da pesquisa científica. São Paulo: Cultrix, 1972.

RUSSELL, Bertrand. Los Princípios de la Matemática. ESPASA-CALPE, Buenos Aires, 1948.

SANTOS, Almir Rogério Silva; VIGLIONI, Humberto Henrique de Barros. Geometria Euclidiana Plana. Universidade Federal de Sergipe, CESAD. São Cristóvão/SE, 2011.

SILVA, Lenise Júlia Fassini da. Ensino de Geometria Projetiva e Perspectiva: Um olhar pelas Fotografias. (Dissertação). Vitória: UFES, 2018. 